\title{
A Psicologia Revisitada pela Pragmática: Subjetividade, Conhecimento e Método
}

\author{
Pedro Fernando Bendassolli ${ }^{12}$ \\ Universidade de São Paulo
}

\begin{abstract}
Resumo
O objetivo deste artigo é discutir as contribuições que poderiam resultar de uma apropriação do referencial da filosofia neopragmática da linguagem para a análise das pressuposições teóricas e metodológicas da Psicologia, tais como as de subjetividade, de conhecimento e de método. Por meio de um estudo teórico, são discutidas as noções de representação, de objetividade e de conhecimento e suas relações com a Psicologia. O artigo também discute as principais características do que, em filosofia, se chama de metafísica da subjetividade: um conjunto de crenças que implicam na busca por fundamentos, na busca por um estado em que seja possível apreender a real essência das coisas. A principal conclusão do artigo é a de que se torna necessário uma ampla redefinição e reavaliação daquelas pressuposições em Psicologia que já não correspondem mais à atual fase de discussões acerca do conhecimento, do método científico e de sua relevância para a comunidade humana.

Palavras-chave: Neopragmatismo; conhecimento; representação; metodologia; subjetividade.
\end{abstract}

\section{Psychology Revisited by Pragmatics: Subjectivity, Knowledge and Method}

\begin{abstract}
The goal of this paper is to discuss contributions that could result from an appropriation of the neopragmatic philosophy of language for the analysis of theoretical and methodological assumptions of Psychology, such as subjectivity, knowledge, and method. By means of a theoretical study, the concepts of representation, objectivity, and knowledge, and their relation to Psychology are discussed. The paper also discusses the main characteristics of what is called, in philosophy, the metaphysics of subjectivity: a set of beliefes that implies the search for foundations, that is to say, the search for a state in which it is possible to apprehend the real essence of the things. The paper's main conclusion is the need for a wide redefinition and reevaluation of those assumptions in Psychology that no longer correspond to the current phase of discussions concerning knowledge, scientific method and their relevance for the human community.

Keywords: Neopragmatism; knowledge; representation; methodology; subjectivity.
\end{abstract}

A Psicologia é uma ciência moderna. Como tal, foi influenciada pelo discurso que construiu a época moderna, discurso que versa sobre o papel e a natureza do conhecimento, sobre o lugar do sujeito na produção desse conhecimento e sobre as condições adequadas e necessárias para que um grupo de enunciados possa ser classificado como científico, como dizendo algo de mais verdadeiro sobre a realidade do que outros grupos de enunciados classificados como não-científicos. Sendo assim, o conhecimento psicológico é chamado a ser científico no sentido exato de que possa dizer algo sobre a realidade psicológica de maneira clara, segura, fundamentada e passível de aplicações práticas a vastas áreas da existência humana.

A preocupação da Psicologia tem sido, há muito tempo, com o rigor e com o desejo de sustentar vocabulários que descrevam a "natureza da psique", a "natureza do comportamento humano individual ou em grupo", a

\footnotetext{
${ }^{1}$ Endereço para correspondência: Rua Campos Salles, 2494, 13416 310, Piracicaba, SP. Fone: (13) 4332830.E-mail: pedrofernando@terra.com.br ${ }^{2}$ Projeto apoiado pela Fundação de Amparo à Pesquisa do Estado de São Paulo, FAPESP.
}

"natureza dos laços ou vínculos pessoais", a "natureza da subjetividade" etc. Embora influenciada pelos discursos de outras ciências sociais, a Psicologia se mantém vinculada à tarefa moderna de busca da verdade, de estabelecimento de relações entre fatos e teorias, e de fusão entre um conhecimento assim produzido e sua capacidade de transformação social, sua capacidade de ser útil e funcional. Por que as coisas estão neste nível? Por que existiria este discurso quase-intuitivo, facilmente socializado nas Faculdades e nos grupos de pesquisa científica, de que a Psicologia tem de prestar contas do conhecimento em sua modalidade moderna? Isto é, de um conhecimento que consiga espelhar, de modo acurado, a realidade investigada?

Neste artigo vou discutir a produção de conhecimentos em Psicologia, a partir do ponto de vista da filosofia neopragmática da linguagem. O objetivo é realizar um debate crítico sobre o tipo de visão de conhecimento que alimenta algumas das práticas dentro do campo psi. Para tanto, vou me deter na explanação das principais contribuições trazidas por Rorty (1979) ao estudo do conhecimento, da verdade, da representação e dos fundamentos metodológicos que dariam ao saber psicológico o status de representante 
confiável da natureza investigada - no caso, da "natureza psicológica". Em seguida, vou discutir como a noção de "mente" funcionou, ou talvez funcione, como um pressuposto necessário à produção do conhecimento dentro de uma certa perspectiva filosófica, justamente aquela que postula o conhecimento como um conjunto de representações que são conhecidas graças ao "olho interno" da própria mente, que inspeciona tais representações e lhes atribui valor de verdade - conforme estejam ligadas ao mundo ou tenham sido produzidas por uma metodologia livre de quaisquer tipos de "vieses" ou "distorções" não-cognitivas. A partir deste ponto vou defender a hipótese de que a noção de "mente" - e da produção de conhecimento a ela ligado - pode ter se deslocado para a noção, psicológica, de "psique", ou de "personalidade", enfim, para qualquer noção que implique certa permanência, "essência" ou natureza dada a priori à investigação.

Outra finalidade deste artigo é discutir as principais noções que deram origem ao que, em filosofia, se chama de "metafísica da subjetividade", justamente o tipo de orientação teórico-metodológica que acredita na capacidade, possuída pelo ser humano, de apreender universais e de alcançar as essências imutáveis das coisas, inclusive de si mesmo. O ser humano, nesta perspectiva, é dotado de racionalidade e consciência, bem como de faculdades especiais capazes de o diferenciar dos outros animais. O principal argumento é apontar que, apesar de muitas vezes se dizer contrária à metafísica da subjetividade (esta em que a consciência é o pivô da excelência humana, e o sustentáculo da cultura), a Psicologia confunde as noções de sujeito com a de indivíduo. A confusão, como se verá adiante neste artigo, acontece quando se misturam as noções filosófica de sujeito com a sociológica de indivíduo, pois a primeira foi uma invenção moderna ("moderna" no sentido de referência histórica à época moderna) e metafísica destinada a funcionar como fundamento transcendental do conhecimento, como o pensaram Descartes e Kant, ao passo que o indivíduo é a "unidade empírica" contingente que se forma nas diversas épocas e estruturas sociais da modernidade (ele não visa a "fundamentar" nada!). Desse modo, a noção moderna de indivíduo, quando confundida com a de sujeito, revela uma confusão que fez da consciência (ou da "mente") o ponto arquimediano de toda a cultura e de todo o conhecimento, em outras palavras, fez do "homem" (no sentido que foi dado a esta palavra no Iluminismo) um Universal, capaz de ir além de meramente fornecer justificativas para se acreditar na verdade de um conhecimento para identificar, por detrás do véu das idéias e das aparências, o conhecimento verdadeiro, necessário, imutável e profundo das coisas e da natureza.

\section{A Invenção da Mente e a Teoria do Conhecimento}

Tratar deste tópico a partir do Philosophy and the mirror of nature (Rorty, 1979) é levantar uma tradição filosófica antiga. A invenção da mente foi o passo inicial indispensável para trazer para a cena filosófica a noção de conhecimento enquanto um conjunto de representações privilegiadas e de epistemologia como a tentativa de garantir a adequação destas representações com a realidade representada. Segundo aponta Rorty, a noção de mente foi inventada por Descartes, no século XVII, para funcionar como um campo prévio de inquirição, um campo onde a certeza se oporia à mera opinião. A mente é o espaço interno, local privilegiado onde o conhecimento verdadeiro pode ser construído e avaliado enquanto tal. Descartes legou para a tradição filosófica posterior a idéia de que somente através de um exame acurado, feito pelo "olho interno da mente", poder-se-ia discernir o que deveria contar como verdade. O método foi a decorrência necessária para garantir o espelhamento sem manchas da realidade no espelho interno da mente. Mas, continua Rorty, a epistemologia só chegaria à maturidade com Kant, a partir do momento em que ele postula que só podemos saber, a priori, sobre os objetos se os constituímos por meio de nossas faculdades, identificando o tema central da epistemologia como sendo o das relações entre duas espécies de representações igualmente reais, mas irredutivelmente distintas: as "formais" (conhecimentos) e as "materiais" (intuições).

Como diz Rorty (1979), a epistemologia foi concebida como a busca, iniciada no século XVII por Descartes, daqueles itens privilegiados no campo da consciência que são, por assim dizer, as pedras de toque da verdade. $\mathrm{O}$ ideal da epistemologia é um ideal de autopurificação (Rorty, 1982), isto é, uma meta para se buscar a aproximação mais estreita possível entre o conhecimento e a realidade da qual ele trata. A mente foi, no século XVII e subseqüentemente, tornada uma esfera autocontinente de inquirição, pois a idéia era oferecer um tipo de relato para-mecânico dos processos mentais que iria, de alguma forma, subscrever algumas afirmações de conhecimento e desaprovar outras (Rorty, 1979). A partir da noção de mente como um espaço privilegiado de investigação estabelece-se também uma dicotomia entre o sujeito (que detém uma capacidade "constitutiva") e o objeto (que é "imposto" à consciência por meio da intuição ou dos sentidos). Kant concebia o conhecimento como uma síntese dos aspectos apriorísticos das faculdades transcendentes e os aspectos meramente intuitivos, uma vez que influenciados pelo sentidos. Neste esquema, que perdurou pela geração posterior a Kant, o "dado" (regido pelas intuições) é contingente, ao passo que aquilo que é acrescentado pela mente é o "conteúdo" (regido pelos conceitos). Posteriormente, surge a longa série de 
dicotomias que permeariam a história do pensamento científico ocidental, tais como a dicotomia entre fato e valor, teoria e prática, objetivo e subjetivo, descoberto e inventado, ciência e ideologia, qualitativo e quantitativo etc.

Uma das observações centrais de Rorty (1979) consiste em dizer que o pensamento filosófico ocidental tem estado cativo de metáforas perceptuais ou oculares acerca do conhecimento e da própria atividade filosófica. Segundo tal metáfora, o objeto do conhecimento impõe a verdade de uma proposição, assim como a presença de uma vela acesa impõe a sua imagem na retina do olho de quem está, contingentemente, diante dela. A idéia de "verdade necessária" é apenas a idéia de uma proposição que merece crédito porque o "domínio" do objeto é inelutável sobre aquele que se propõe a investigá-lo. Assim, prossegue Rorty, a imagem ocular tem impregnado a maior parte da tradição filosófica posterior a Platão, Descartes e Kant, e sem dúvida impregna também nossa própria concepção moderna do que seja o "conhecimento".

Com base na metáfora ocular, incorporada depois na noção de um "olho da mente" que inspeciona as representações internas do sujeito, o conhecimento é uma questão de relacionamento com uma realidade não-humana (com um "objeto" do mundo). Para se assegurar que um grupo de representações teria, ou não, o direito de ser chamado de "verdadeiro" (já que adequadamente espelharia a realidade), criou-se o que Rorty (1979) chama de "fundamentos do conhecimento". Esta necessidade por fundamentos pode ser decomposta em quatro figuras magistrais, responsáveis por sua criação e instituição. Primeiro, o próprio Platão, que dizia que o conhecimento só era alcançado escapando-se dos sentidos e abrindo a faculdade da razão - o Mundo da Alma - ao Mundo do Ser. Em seguida, Descartes, para quem o conhecimento só poderia ser obtido ao se desviar o Olho da Mente das confusas e ludibriantes representações internas para aquelas claras, distintas e honestas. Terceiro, Locke, que afirmava que o conhecimento era alcançado se encaramos as "apresentações singulares ao sentido" como o que deveria "agarrar-nos" - ao que, enfim, não poderíamos e não deveríamos escapar. Por fim, Kant, para quem o conhecimento se tornaria a busca pelas regras que a mente havia colocado para si mesma, os chamados Princípios do Entendimento Puro. Este amplo conjunto de formulações ampara-se na analogia entre perceber e conhecer, em resumo, na metáfora ocular segundo a qual a mente é um espelho da natureza.

A metáfora da mente como um espelho alimenta o que Rorty (1979) chama de teoria do conhecimento moderna, baseada em três afirmações: 1) as crenças são determinadas por sermos trazidos frente-a-frente do objeto da crença (a figura geométrica que prova o teorema, por exemplo); 2) para saber como conhecer melhor é preciso saber como melhorar a atividade de uma faculdade quase-visual, o Espelho da Natureza, e assim pensar no conhecimento como uma montagem de representações exatas; 3) a maneira para se obter representações exatas é encontrando, dentro do espelho, uma classe privilegiada de representações, tão determinante que sua exatidão não possa ser posta em dúvida. A teoria do conhecimento, segundo Rorty, seria a busca por aquilo que é visto como uma representação acurada, exata, da realidade, e cabe à epistemologia determinar os requisitos a partir dos quais são examinadas as condições em que o conhecimento, assim concebido, é encontrado e revestido com valor de verdade. Em resumo, a epistemologia é a tentativa de aprender mais do que podemos (a essência especular das coisas) e de conhecer as coisas a partir do conhecimento de como a própria mente funciona.

Como diz Rorty (1982), a visão do que seria o conhecimento epistemologicamente calcado alimenta uma outra visão paralela: uma visão segundo a qual a ciência seria descrita como convergência até um ponto final chamado de "correspondência com a realidade". Isto se baseia no que Rorty chama de "fantasia filosófica arquetípica", concebida primeiramente por Platão, de abrir caminho entre todas as descrições, entre todas as representações, até um estado de consciência que combine o melhor da visão inefável com o melhor da formulação lingüística. Isto restringe a concepção de linguagem, pois esta deixa de estar sob o crivo do estilo, particular a cada agente ou a cada linha de investigação científica (como a Psicologia), para ser diretamente determinada pela afinidade à linguagem própria da natureza em questão. Os estilos podem variar, mas a concordância com a realidade subjacente, isso não pode variar de forma alguma.

Até aqui me detive na argumentação de Rorty (1979) concernente à invenção de um local metafísico - a mente - para abrigar a tarefa de examinar a qualidade e a natureza do conhecimento tido como um aglomerado de representações internas exatas de uma realidade externa espelhada (ou seja, representada, acuradamente, no Espelho da Natureza). A epistemologia, que chegou à maturidade filosófica com a distinção entre "necessário" e "contingente", feita por Kant, encarregou-se de fundar e restringir a procura de conhecimento. Fundar este último na certeza da mente enquanto um olho que vê exatamente como é a realidade; restringir, pois somente se encaixam como conhecimento as representações que foram aprovadas por tal olho. Ademais, a epistemologia é restritiva pois pretende separar e escolher representações privilegiadas e aquelas que não o são de forma alguma, dada a própria natureza da 
mente como tribunal da verdade. Numa versão moderna desta face da epistemologia, encontramos o debate entre discursos mais ou menos "científicos", em vista de sua habilidade em dizer mais ou menos bem qual é a real essência das coisas estudadas.

No que segue darei continuidade à linha de argumentação desenvolvida anteriormente, destacando algumas das principais características do que, em filosofia, se chama "metafísica da subjetividade" (termo originalmente cunhado por Heidegger). Tal subjetividade foi uma invenção moderna, arquitetada principalmente por Descartes, para construir uma base para o conhecimento; em outras palavras, ele criou a noção de um sujeito do conhecimento, cujo fundamento está na noção de mente, de representação e de método.

\section{A Metafísica da Subjetividade e a Representação}

A subjetividade moderna é uma invenção filosófica constituída a partir dos fundamentos principais da teoria do conhecimento, tal como exposta na seção anterior. Neste sentido, ela mantém como característica principal a idéia de que existe uma "mente" capaz de servir de campo prévio e necessário a toda e qualquer inquirição dita científica - ou a qualquer outra inquirição com potencial para ocupar o banco da verdade. Pode-se desmembrar a metafísica da subjetividade (a partir de um discurso filosófico) em duas crenças principais:

a) $\mathrm{Na}$ crença na representação, compreendida como um espelhamento mental da realidade. A representação é uma atividade do sujeito do conhecimento, o qual é capaz de traduzir aspectos não-lingüísticos do mundo (coisas, "objetos" etc.) em imagens mentais claras e distintas umas das outras (ou seja, é capaz de discernir sobre aquelas representações que são mais ou menos privilegiadas). Representar é uma atividade consciente, uma conseqüência da ação reflexiva da mente do sujeito epistemológico, isto é, do sujeito como juiz do verdadeiro e do falso, o detentor da linguagem e do pensamento conceitual. Sujeito e objeto, nesta perspectiva, estão metafisicamente separados: o primeiro age, o segundo sofre a ação do primeiro e pode ser por ele manipulado. Esta é a versão iluminista da noção de subjetividade;

b) $\mathrm{Na}$ crença, derivada de Rousseau, de que há um núcleo inefável dentro do ser humano, centro de experiências e sentimentos que não podem ser partilhados, mas somente conhecidos pelo contato entre o sujeito e seu próprio coração. Com Rousseau a intimidade assume a relevância que o método racional tinha para Descartes, pelo menos no que toca ao estabelecimento do valor de verdade dos enunciados ou representações. O que está em questão aqui é a noção de "homem natural", que possui o centro primitivo de uma razão natural, a qual se conecta com as idéias tradicionais de essência, espírito ou verdade inerentes à subjetividade. Este centro é a fonte a partir da qual se originam as coisas e pelo qual o sujeito cresce e se desenvolve enquanto ser humano. Esta é a versão romântica da noção de subjetividade.

A subjetividade, desde que entendida como um conceito filosófico-metafísico preparado para tornar possível um certo tipo de conhecimento - representacional -, é formada pelo "Eu penso", de Descartes; pelo "Eu sinto" (de sentimento) de Rousseau; e pelo "Eu experimento" (de sensação) de Locke. Do lado de Descartes se nota um modelo particular de subjetividade mais próximo ao Iluminismo (a verdade é dada ao sujeito do conhecimento), ao passo que do lado de Rousseau se insinuam os fundamentos do Romantismo (a verdade se desloca do Cogito e é acessada pelo assentimento do coração, tornandose algo eminentemente íntimo e incomunicável) (Ghiraldelli Jr., 2000). Para ambos, entretanto, a subjetividade é ativa, sendo a sede da razão ou do sentimento, capaz de identidade consigo mesma e de estabelecer direitos, virtudes e, principalmente, a verdade.

Descartes e Rousseau apresentam, assim, modelos de subjetividade distintos e particulares. Como diz Ghiraldelli Jr. (2000), é possível abstrair estes modelos de modo a se pensar numa espécie de modelo geral de subjetividade, que é aceito pela maioria dos pensadores modernos. Desse modo, afirma Ghiraldelli Jr., a subjetividade pode ser desmembrada e descrita de acordo com "níveis de consciência", sendo eles: o Eu, a pessoa, o cidadão e o sujeito epistemológico. O Eu é a marca da identidade do sujeito, fluxo temporal de estados corporais e mentais. Ele é capaz de reter o passado, perceber o presente e projetar o futuro; é o centro ou unidade de todos esses fluxos, também considerado como consciência psicológica, formada pelas vivências pessoais. Este $E u$ permanece intocado diante do mundo e é, ao mesmo tempo, produtor, organizador e reorganizador de nossas experiências sensíveis, intelectuais e racionais. A pessoa é a consciência moral, sujeito que discerne entre o certo e o errado, entre o bem e o mal. O cidadão é a consciência política, o sujeito como juiz dos direitos e deveres. O sujeito epistemológico é a consciência intelectual, o sujeito como juiz do verdadeiro e do falso; trata-se da consciência em sua modalidade mais universal. Escreve Ghiraldelli Jr.:

A subjetividade assim composta, considerada a consciência que se manifesta nessas quatro formas principais, é a instância da qual o homem (empírico ou abstratamente genérico) deve participar. Se conseguir isso, autenticamente, torna-se o sujeito - 'aquele que é consciente de seus pensamentos e responsável pelos seus atos' (pp. 23-24) [ grifos do autor].

Para o conhecimento chegar a ser "verdadeiro", ele deve ser crivado pela certeza subjetiva fornecida pelos critérios 
de verdade da "metafísica da subjetividade". Por conseguinte, tal metafísica funciona como um dispositivo de legitimação moral e intelectual do saber, um tipo de fundacionismo filosófico que tenta converter o ser humano, o "homem" (no jargão iluminista/humanista), em sujeito, quer seja na vertente iluminista/cartesiana (item "a"), ou na vertente humanista/romântica (item "b”). Ambas possuem pedagogias próprias para levar a cabo essa conversão, para se trazer à luz o "verdadeiro" sujeito e sua "verdadeira natureza”. É importante registrar que essa conversão, essa passagem, do ser humano a sujeito produz, ao mesmo tempo, o indivíduo moderno. Ou seja, os seres humanos concretos, à luz da "metafísica da subjetividade", devem alcançar aquilo que, metafisicamente, o fora destinado enquanto uma criatura pensante/racional (vertente iluminista) ou enquanto uma criatura que deve visar à liberdade, ao sentimento, à comunhão consigo mesmo e com seu íntimo (vertente romântica). Esta fusão entre as noções de sujeito e indivíduo serão discutidas um pouco à frente neste artigo.

Rorty (1991a) chama a atenção para um terceiro tipo de subjetividade, que ele designa como o modelo neokantiano. Como diz Ghiraldelli Jr. (2000), "Este, o modelo neokantiano, é mais complexo que os de Descartes e Rousseau. Em vez de manter um 'eu' com apenas periferia e centro, o modelo neokantiano põe um 'eu' dividido em três camadas: periferia, campo médio e núcleo" (p. 51). Rorty (1991a), por meio de um esquema visual, traça o modelo neokantiano da subjetividade como composto por três esferas concêntricas: a primeira, mais em contato com a realidade exterior - o mundo físico abriga o "Eu exterior", rodeado pela contingência e por asserções, proposições etc., passíveis de serem facilmente abandonadas, uma vez que não importam tanto quanto a camada mais interna, justamente a segunda esfera, ocupada pelo "Eu intermediário", o qual contém, a priori, crenças e desejos responsáveis pela "estruturação" ou pela constituição da primeira esfera. Por fim, a terceira esfera, aquela localizada no campo mais interior, é habitada pelo "Eu interior", ou pelo "Eu verdadeiro", o tipo de Eu inescrutável e inefável, compondo o núcleo do sujeito, sua verdadeira essência. Como advoga o próprio Kant, este núcleo - ou "Eu verdadeiro" - não pode ser confundido com os demais elementos da estrutura (com as duas outras esferas), pois ele é transcendental, inincapturável por qualquer teoria ou rede de crenças e desejos contingentes. Pelo contrário, é este Eu que "contém" as crenças e desejos que formam os outros "eus" das demais esferas da subjetividade.

Este modelo neokantiano de subjetividade leva em conta aquilo que, na seção anterior, se afirmou a propósito da divisão contingente/conteúdo, ou intuição/conceitos, ou mesmo entre esquema/conteúdo. Estas dicotomias são reduzidas no mesmo radical da invenção moderna da mente e da epistemologia como marcas registradas do status superior do homem diante dos outros animais, isto é, sua capacidade de, a um só tempo, entrar em contato com a "realidade exterior" e transcendê-la graças a sua capacidade de apreender universais, de enxergar por detrás das aparências, ou então graças a sua capacidade de efetuar "sínteses" entre intuições e conceitos a priori (capacidade de “constituir"'os conceitos). Kant, conforme comenta Rorty (1979), ficou a meio caminho no abandono da tradição que lhe era anterior, principalmente vinda de Locke, de que os objetos "impõem" as "suas" representações sobre a mente, que, diante de tão poderosa influência, não teria outra saída senão a de se agarrar a elas. Fica a meio caminho porque, ao advogar o fato de que o conhecimento é sempre conhecimento para uma consciência, ele abre as portas para uma espécie de idealismo - para o qual a noção de "Eu verdadeiro" faria o serviço de constituir o mundo tal qual ele seria apreendido pelos universais categóricos das chamadas "faculdades transcendentais" do entendimento.

O modelo de subjetividade kantiano, dessa forma, preserva a metáfora ocular intacta, no sentido de que ainda preserva a noção de que temos uma faculdade capaz de representar as coisas de modo exato ou acurado (embora o modelo kantiano tenha sofisticado tal atividade representacional). Isto pode ser mais bem compreendido ao se considerar as formas de relação que Kant imagina existirem entre o sujeito assim retratado (ou melhor, entre a subjetividade assim retratada) e o mundo físico, a realidade externa. Três destas relações merecem destaque aqui: primeiro, a linha da representação - Kant, como a tradição que ele encontrou, acreditava no princípio, já apresentado neste texto, de que o sujeito poderia traduzir o mundo em palavras que melhor o representassem no espaço interno da subjetividade (na mente, ou no "espelho da natureza"). Esta idéia pressupõe outra: a mente como um teatro que reproduz, internamente, coisas exteriores. Neste caso, haveria então melhores ou piores representações, o que equivale a dizer que haveria formas melhores ou piores de dizer como as coisas realmente são. A segunda forma de relação entre sujeito-mundo é a da constituição que pressupõe a existência de verdades mais essenciais do que outras, que seriam, assim, contingentes. As verdades necessárias - ou essenciais - teriam esta característica por não dependerem, para sua existência e/ou validade, dos dados empíricos. Na versão kantiana, verdades necessárias são não-contingentes e estão localizadas na esfera média do seu modelo de subjetividade. Por fim, uma última forma de relação é a que torna as sentenças ou as representações verdadeiras, ou seja, é a forma de relação caracterizada pela verificação - "o evento no qual algo na realidade é emparelhado 
com uma frase que em princípio lhe corresponderia, autorizando-a a qualificar-se como verdadeira - como perfeitamente correspondente a 'algo na realidade" (Ghiraldelli Jr., 2000, p. 58). Com base numa crítica a estas três formas de relação sujeito-mundo, Rorty $(1979,1991$ a) irá descrever sua visão naturalizada e holística da subjetividade.

Este quadro filosófico que acabo de traçar em relação ao conceito de "metafísica da subjetividade" é útil por manter em vista a diferença, algumas vezes negligenciada, entre esta noção e a noção, de cunho sociológicopsicológico, de individuo. Ao que cumpre acrescentar neste texto, é minha intenção discorrer sobre a confusão entre estes dois conceitos - que pode estar seguindo em curso em alguns discursos da Psicologia atual, principalmente no que toca à questão do método. Esta confusão faz com que uma certa tradição filosófica, exatamente aquela iniciada por Platão, perseguida por Descartes e consolidada por Kant, dite uma visão de conhecimento que, dentro pelo menos de uma certa perspectiva filosófica (em especial na neopragmática de Rorty), tem sido alvo de intensas críticas e redescrições. É neste ponto que acredito que uma assimilação consciente do trabalho de Rorty (1979, 1982, 1991a, 1999) convida a uma séria e abrangente redefinição de conceitosbase que sustentam certas teorias da Psicologia e mesmo certas teorias das Ciências Sociais nos dias de hoje. É esta metafísica da subjetividade que, escoada para a Psicologia principalmente por meio do método, mantém velhas dicotomias da época moderna, tais como sujeito-objeto e linguagem-mundo, donde uma possível origem da obsessão que muitos psicólogos têm com relação ao método que melhor se "adapte" ao "objeto de estudo" em questão.

Uma explicação para o porquê de haver uma tal confusão entre a noção - metafísica - de sujeito, com seus enraizamentos na teoria da mente e do conhecimento como espelhos da natureza, e a noção de indivíduo, pode ser dada lembrando que as chamadas Ciências Sociais são temporalmente posteriores à fusão filosófica entre a noção de sujeito, aquilo que fica, que permanece, e a de indivíduo - homens e mulheres que agem segundo as pressuposições do sujeito filosófico: conscientes, tomam decisões, são a base da lei e detêm responsabilidades diante de seus atos. Um indício deste fato pode ser remotamente encontrado no surgimento concomitante entre, de um lado, o romance - típica história de indivíduos - e, de outro, a própria noção de sujeito na filosofia, tal como a apresentei antes. $\mathrm{O}$ Romantismo, apoiando-se nas noções de Rousseau, mantém, ele também, a noção de que alguma coisa permanece, de que alguma coisa sub-jaz (subjectum): no caso, o que permanece é a alma interna ou o Eu interior, a parte mais íntima do sujeito - que permanece e que pode ser um terreno prévio de inquirição (no caso de Rousseau, a "verdade" está no coração).

Para ficar mais claro o modo como ocorre a referida fusão, basta dizer que o sujeito é um ideal metafísico, ao passo que o indivíduo é formado nas diversas épocas e estruturas históricas. Sujeito, tal como vem sendo descrito neste artigo, é uma noção filosófica, cuja constituição podemos encontrar na filosofia de Descartes. O sujeito, nesta filosofia, é abstrato e universal, um ideal a que todos devem chegar para serem "verdadeiramente humanos". O sujeito não tem um rosto, não tem uma história, não é contingente e não pode ser visto; não é um ser concreto, mas uma abstração. Descrito na semântica do iluminismo e do humanismo, é aquele que é "consciente de seus pensamentos e responsável pelos seus atos"; é a razão, a consciência, o Eu. Em contrapartida, podemos acompanhar o surgimento do indivíduo por meio dos estudos clássicos de Norbert Elias (Elias, 1982/1993). Em Norbert Elias acompanhamos como o indivíduo, independentemente de ideais metafísicos a priori, se constitui na base de distintas regras socializatórias, que variam ao longo do tempo e em função de grupos sociais concretos. Nesta perspectiva, o indivíduo, ao contrário do sujeito, não fundamenta nada, não serve de base para o estabelecimento da verdade dos diversos saberes; ele é circunscrito e tem, digamos assim, uma "face". Ele, inclusive, é descrito num outro vocabulário e segundo outras orientações, a saber, o vocabulário das Ciências Sociais, originalmente preocupadas em trazer o sujeito (filosófico) para o chão, em dar-lhe corpo e substância.

Contudo, as Ciências Sociais, ainda que utilizando o vocabulário do indivíduo, muitas vezes se prendem, explícita ou implicitamente, à noção filosófica de sujeito, e isto da seguinte forma. Quando descrevem o indivíduo, geralmente o fazem atribuindo a ele características que pertencem, originalmente, ao sujeito filosófico: descrevem o indivíduo como "consciente de seus pensamentos e responsável pelos seus atos", como "dono de si”, como devendo alcançar um certo ideal para então realizar-se como um "humano verdadeiro", como possuindo um núcleo inefável, inescrutável e mais essencial do que outros, como portador de crenças necessárias e de crenças contingentes e como separado da realidade natural por uma província especial, a razão, a capacidade de representar o mundo de modo exato. Apesar de falar de seres concretos, homens, mulheres, crianças, idosos, jovens etc., muitas das teorias das Ciências Sociais fundem as duas noções, fazendo respingar no indivíduo a metafísica que deu origem ao sujeito ou à subjetividade modernos. E, pelo método, tais teorias acreditam acessar, sem a distorção da "influência humana", a Linguagem da 
Natureza que investigam. Um exemplo talvez ajude na compreensão do que estou a dizer.

A Psicologia, sendo uma ciência voltada para o estudo de indivíduos, pode, ao invés de descrever a subjetividade como algo contingente e gerido dentro de uma prática lingüística histórico-social particular, dizer que o indivíduo é a incorporação de um tipo de ideal que deve ser alcançado para se chegar ao que realmente condiz com a condição humana, ao que verdadeiramente devemos aspirar ou ao que realmente devemos contar como subjetividade etc. Estamos diante de uma confusão entre as noções de indivíduo e sujeito sempre que acreditarmos que nossas definições do humano, da subjetividade, são mais do que descrições motivadas por interesses e finalidades próprios, concretos, "disciplinares" (no sentido dado a este termo por Foucault), toda vez que acreditarmos que são verdadeiras descrições do Humano, partilháveis por todos os seres dotados de razão, sentimento, de um Eu ou de uma identidade. A confusão aparece no instante em que tentamos dar apoio ou fundamento à nossa descrição da individualidade ou do indivíduo para além de nossas teorias presentes e de nossos interesses particulares, circunscritos; toda vez que escoramos nossas definições de individuo (ou da subjetividade) na metafísica, e baseamos nossa investigação na busca de conhecimentos crivados pela metafísica da subjetividade, pelo ideal universal do que seja, verdadeiramente, o ser humano, a personalidade, as condutas humanas, o desenvolvimento humano, o comportamento etc., noções estas tão caras à Psicologia desde seus primórdios.

As Ciências Sociais, em muitas de suas teorizações nascentes, apesar de se insurgirem contra a metafísica através da tentativa de trazer o sujeito para o chão das ciências empíricas, incorporaram a noção metafísica e filosófica de sujeito. E a própria Psicologia (aqui não compreendendo a psicanálise que é, tradicionalmente, associada à crítica da subjetividade moderna ao atacar a noção de consciência como marca distinta do homem - Bezerra Jr., 1994; Rorty, 1999) adotou algumas das pressuposições da chamada metafísica da subjetividade, tais como o fato de ser o sujeito o senhor de seus pensamentos (consciência), o responsável por seus atos (vontade) e o fato de ser ele "universal", imutável, abstrato, e fundiu-as com alguns de seus conceitoschave, tal como o próprio conceito de indivíduo, de Eu e de personalidade, por exemplo (ou de qualquer outro conceito que implique na idéia de que algo permanece, de que é mais "intrínseco" do que outras coisas, mais "profundo", "estruturante", "necessário" etc.). É também devido a esta confusão que muitas pessoas interpretam as críticas que são feitas a este modelo como uma tentativa de "matar o sujeito", pois não entendem a fusão feita entre uma noção filosófico-metafísica, criada para fundar uma teoria do conhecimento (esta sim sob ataque de violentas críticas - tal como feito por Rorty, 1979), com os conceitos de indivíduo, classe social, grupo etc., forjado nas Ciências Sociais e na própria Psicologia para dar conta de fenômenos contingentes.

O mais importante é notar que muitas das afirmações da metafísica da subjetividade podem persistir na preocupação da Psicologia com o método e com o rigor objetivos - basta ver a controvérsia que se estende desde há muito tempo, por exemplo, entre as metodologias ditas qualitativas e quantitativas, muitas vezes fazendo o debate pender a favor das metodologias quantitativas, à luz de uma imitação do método das ciências naturais. Será preciso um esforço de desconstrução e desfamiliarização teóricos para limpar de vez do pensamento psicológico o que Rorty (1982) chama de desejo de autopurificação, isto é, o desejo de sustentar alguma garantia para o valor de verdade dos enunciados e práticas por ela produzidos, apoiando-se em algo como a epistemologia enquanto "espelho da realidade" (o que era feito no século XVII nas formulações de Descartes) ou a metafísica (no sentido da "metafísica da subjetividade", no sentido da busca por fundamentos para além da linguagem contingente, além da própria comunidade humana, indo até os próprios fatos “em si”, ou à própria Natureza). Além do mais, é sobre a mencionada fusão entre sujeito e indivíduo que recaem boa parte das críticas contemporâneas aos fundamentos da ciência moderna, principalmente a crítica à metafísica, à epistemologia e à objetividade (tal como compreendida em sua versão "moderna", a saber, de ser a objetividade um ponto neutro de investigação, capaz de abrir caminho entre as representações falsas da realidade). Vejamos como isso fica no caso da Psicologia.

\section{A Psicologia Moderna e a Preocupação com o Método}

É possível incorporar as idéias apresentadas nas duas seções anteriores para agora fazer uma discussão sobre a possibilidade de elas estarem a sustentar boa fatia do discurso psicológico, principalmente o discurso sobre o método, em especial o método "positivista". Isto ocorre por meio da instituição de alguns conceitos-chave dentro do corpo de conhecimentos veiculado pela Psicologia, os quais passarei a analisar.

$\mathrm{Na}$ linguagem corrente do pensamento epistemológico ocidental, a Psicologia, como qualquer outra área de conhecimento, para ser chamada de "científica", tem de seguir uma certa seqüência de procedimentos. Em primeiro lugar, tem de possuir um "objeto", isolando-o dentro do amplo campo lingüístico moderno (isto é, dentro das várias 
linguagens "científicas" sobre o humano), e tem de dizer que este "objeto" é, de certo modo, um "recorte" do "real" - pelo menos daquele "real" sobre o comportamento, a subjetividade etc. Em outras palavras, isso quer dizer que a Psicologia tem de dizer algo de diferente e especial sobre alguma coisa da existência humana que não seja dito por nenhuma outra ciência ou não-ciência. Ao identificar seu objeto precisa, então, compor um quadro de definições, conceitos e pressupostos que formam um tipo de vocabulário, que passa a sustentar uma certa imagem de homem ou de sujeito. Produz discursos, falas; prescreve formas de se comportar ou de se encarar a "natureza humana", as classificam, as legitimam ou então as desautorizam enquanto representantes da realidade investigada. Mas qual é a ordem a ser seguida? Postular ou descobrir - um objeto e então falar sobre ele?

Supondo que não haja circularidade, nem uma tautologia operando aqui, pode-se dizer, a partir do senso comum do pensamento epistemológico moderno, que o "objeto" da Psicologia sempre "esteve ấ", sempre esteve ao nosso lado, só que não era reconhecido, catalogado. Seria mais ou menos como uma nova espécie vegetal: estava sempre aí existindo, só que até então não havia sido classificada, portanto, não havia sido descoberta. As palavras aqui não são ao acaso: "descoberta", e não "inventada". O "descoberto" traz a idéia de algo que existia previamente à teoria ou à linguagem que, num determinado momento, passou a recobrir aquele objeto sem nome, mas com existência real, concreta. "Descobrir" equivale a "conhecer", a "saber". Com o "objeto" da Psicologia não seria diferente. Portanto, a ordem a ser seguida, para legitimar um discurso ou uma teoria como científica, seria achar o objeto e então nomeá-lo. Neste raciocínio não há lugar para o inverso: não é o nome - isto é, a nomeação - que cria o objeto, mas a própria natureza, algo que estaria além de nossas forças. O nosso trabalho seria simplesmente um trabalho de garimpagem: selecionamos a pepita e então a trabalhamos como desejamos. O método é, em grande parte, o responsável pela descoberta desta pepita. E a pepita, figurativamente falando, pode ser designada como o "objeto psicológico", ou a "natureza psicológica".

A base desta concepção de Psicologia como uma ciência capaz de instituir uma versão "oficial" sobre a "natureza psicológica" é, sem exagero, semelhante à que sustenta o conhecimento como um aglomerado de representações exatas da realidade. É um conhecimento que traduz a realidade em palavras e sentenças, e seu valor de verdade é dado pelo quão confiável for esta ligação entre o real e a palavra que o nomeia. O método, pelo menos dentro desta visão moderna, faz o papel de uma máquina de tradução: ele engancha a palavra ao mundo e, ao fazer isso adequadamente, garante a verdade, a "representatividade" da coisa investigada. Como sustenta Rorty (1979), esta seria uma visão pré-kuhniana de ciência. A verdade, neste caso, baseia-se numa teoria de correspondência entre a palavra e a "coisa" nomeada pela palavra. Está aqui uma possível origem conceitual para as concepções, em Psicologia, que sustentam haver uma espécie de cisão na própria palavra: uma cisão entre o signo - a imagem - e a "coisa" concreta do mundo da "psique" ou da subjetividade etc. Esta concepção sustentou, e tem sustentado, metodologias de pesquisa que literalmente atomizam a palavra e/ou o comportamento para tentar entendê-los a partir de suas conexões intrínsecas com a "realidade".

Esse conjunto de pressuposições filosóficas de base, ligado à invenção da mente, da epistemologia e da representação, pode ser identificado em algumas noçõeschave dentro do campo psicológico em geral. Escrevendo e pensando na mesma linha que sigo neste artigo, o construcionista social espanhol Tomás Ibáñez (Ibáñez, 1993) sustenta que a Psicologia se ampara em algumas noções-chave ingênuas. A primeira, cuja semelhança com a invenção filosófica da "mente" é surpreendente, é a noção de psique. É a partir desta noção que a Psicologia, pelo menos em algumas de suas teorias (o que, obviamente, não inclui a psicanálise), pode enfocar a operação de produção de conhecimentos, isto é, a partir de um tipo de "objeto" que é constituído por um conjunto de fenômenos, processos e mecanismos que compõem a verdadeira realidade psicológica da qual somos feitos. Essa "instância", por assim dizer, "é o que é", independentemente das palavras que usamos para descrevê-la, independentemente dos instrumentos que usamos para acessá-la; enfim, ela é completamente independente de tudo aquilo que possamos vir a conhecer sobre ela.

Aqui se instala o primeiro passo de uma dicotomia tradicional, que explorei nas duas seções anteriores: a dicotomia entre a realidade, por uma parte, e o conhecimento desta realidade, por outra. Trocando em miúdos: isto equivale a dizer que existe uma realidade prélingüística, a priori, que impõe sua essência ou grava suas impressões sobre nós, sobre o sujeito do conhecimento e sua faculdade de ir além das aparências, de apreender a natureza intrínseca desta realidade. Ao contrário de uma visão rortiana (Rorty, 1979), ou kuhniana (Kuhn, 1962) de ciência, não são as convenções lingüísticas ou os acordos estratégicos entre parceiros que determinam o "objeto" de estudo e seus mecanismos constitutivos mas, pelo contrário, é o próprio objeto - no caso, a psique - que determina o rol de protocolos de uma ciência, da ciência psicológica. A linguagem desta ciência passa a ser a Linguagem da própria psique, isto é, do próprio objeto de investigação. Sob a 
influência deste raciocínio geralmente se deixa de lado, por exemplo, a ampla série de fatores históricos e sociológicos que formaram e que têm sustentado o que viemos a compreender e a significar como psique, subjetividade, intimidade, inconsciência, oculto/revelado etc. A genealogia destas palavras, e, principalmente, a genealogia do longo percurso que as tornaram inteligíveis para nós hoje, é simplesmente deixada de lado. No entanto, é justamente tal percurso que revela a contingência de nossos vocabulários, e, inclusive, a contingência de nossos mais caros e estabelecidos "objetos" de investigação, aqueles tidos por verdadeiros já de antemão.

Outra noção-chave da Psicologia é a própria noção de método, ou o que poderíamos chamar, em alguns casos, de "obsessão metodológica", a ânsia por um amplo quadro de procedimentos-padrão que assegurariam, por si só, o peso de verdade dos enunciados psicológicos. O método precisa garantir que o que se está a falar sobre a realidade esteja em correspondência com esta mesma realidade, deva se ajustar a ela, e não o inverso. No caso, o método em Psicologia deve garantir que a chamada "realidade psicológica" esteja sendo representada acuradamente, esteja sendo acessada do modo menos mediado possível, menos influenciado por "fatores pessoais" ou por "fatores residuais” quanto seja possível. Como diz Ibáñez (1993), podemos criar tantas teorias quanto nos seja conveniente fazer, mas serão, em última instância, apenas os fatos que irão pôr um freio a esta capacidade inventiva. Somente eles poderão separar o joio do trigo, isto é, aquilo que é adequado à realidade, aquilo enfim que diz respeito ao real e pode ser acreditado, e aquilo que é pura especulação, ficção de uma mente irresponsável ou, quando muito, enganada ou ingênua. Somente o método poderá nos dar a clarividência sobre qual seja precisamente a distinção entre fato e valor, resguardando o domínio do que Rorty (1982) chama de "privilégio epistêmico" sobre o "privilégio moral". Daqui decorre que, se um conhecimento psicológico não estiver em linha com os fatos, ele se torna sem utilidade, não pode ser útil às pessoas nem ao ambiente em que estas vivem; resumindo: é um conhecimento inútil, ineficaz, distorcido, enviesado, "moral" etc. Em linhas bem amplas, posso destacar as seguintes crenças que sustentam a relação da Psicologia com o método (ou pelo menos de partes da atual Psicologia):

a) A crença de que o método evita o contato humano do pesquisador com o "objeto" a ser investigado. Em outras palavras, o método seria capaz de "gelar" a relação, permitindo o silenciar das particularidades do sujeitopesquisador. Em clínica, sobretudo na clínica psicanalítica, esta relação é trabalhada sobre o conceito de transferência. Em pesquisa, que é o registro mais importante aqui, há diversas filiações metodológicas, mas muitas têm em comum essa crença no poder "impessoalizante" do método. Esta crença positivista, desde ao menos os teóricos pós-estruturalistas (como Foucault, por exemplo), tem estado sob severo ataque, e muitas pesquisas têm partido por outros referencias, como a fenomenologia, o existencialismo, ou então têm incorporado as contribuições das demais ciências sociais, redefinindo o conceito de "objeto" nas teorias que lidam diretamente com a subjetividade humana. Esta crença também pode se amparar na mesma fusão que deu origem ao Humanismo, a saber, a fusão entre o "sujeito" (o subjectum) e o indivíduo, ou entre o sujeito epistemológico-filosófico e o indivíduo concreto, tal como apresentado acima;

b) A crença de que o método permite o acesso a uma verdade que, de outra forma, não viria à luz. Esta crença tem sido discutida em todo este artigo, e tem a ver com a invenção moderna da "mente" e da epistemologia como pontos arquimedianos de todo conhecimento. De um jeito ou de outro, é ainda uma crença forte que sustenta muitas teorias presentes, mesmo tendo sido alterada e transformada de acordo com outras denominações conceituais;

c) Do ponto de vista da convenção, o método faz a separação entre distintas correntes teóricas e linhas de pesquisa. Nesse caso, a crença é a de que o método é determinado pela natureza do objeto sob investigação, e não por um conjunto de regras e acordos estabelecidos entre determinados parceiros da comunidade científica, os quais têm seus propósitos, interesses, objetivos, racionalidade e justificativas próprios. Nesta visão epistemológica ingênua, seria, em última instância, o próprio "objeto" que ditaria aquela linguagem explicativa que melhor se adaptasse à sua Linguagem essencial, no fundo, a própria Linguagem da Natureza. A melhor conformidade entre a linguagem da teoria e a Linguagem da Natureza determinaria o ranking das melhores e piores teorias;

d) Esta crença tem a ver com a primeira e admite que, a um nível básico, o método está dissociado do sujeito-pesquisador (que podemos chamar de agente). Isso determina a forma de produção do conhecimento feita pela pesquisa: os resultados da pesquisa são mais confiáveis à medida que o método for menos dependente do agente que leva a cabo a pesquisa. O método é visto como tendo uma coerência interna que alinhava a pesquisa e imprime a fidedignidade à interpretação dos dados, independente da comunidade lingüística a que pertence esse agente particular. Neste nível, o método opera com "vida própria" e representa um tipo de pensamento que deixou de estar sob debate e discussão e que se familiarizou (ou se "reificou") nas práticas institucionais de pesquisa. A partir 
desta crença se acredita que toda e qualquer interpretação seja, no fundo, uma mera "descrição" de uma realidade acuradamente representada e acessada pelo método. Com esta crença, separam-se "descrever" e "interpretar" que, dependendo do caso, são hierarquizados epistemologicamente, isto é, são "melhores" ou "piores" formas de representar a realidade investigada;

e) Como conseqüência da crença anterior, julga-se que o método está associado à função social da pesquisa. Quer dizer, o rigor e cuidados metodológicos, a ancoragem num conjunto de rituais consolidados e consagrados pela comunidade científica, assegura a eficácia do conhecimento assim produzido. A eficácia, neste caso, não depende de acordos locais, contingentes, entre o agente de pesquisa e o seu "objeto" de estudo, mas depende do desenho da pesquisa do ponto de vista metodológico e de coerência interna, coerência epistemológica. A eficácia não consiste em uma justificativa dada ao conhecimento produzido, justificativa capaz de convencer tantas audiências quanto seja possível (uma prática social), mas em uma garantia do conhecimento enquanto espelho da realidade investigada. Por detrás desta noção de eficácia há um acordo implícito sobre o que signifique a realidade psicológica, a subjetividade, a transformação das pessoas (para melhor ou pior), a ética e a moral, e também um acordo implícito sobre a forma como as pessoas, na academia ou não, aceitam as explicações dadas por essa ciência. A eficácia, nesta visão, tem seu poder determinado, única e exclusivamente, pela crença na capacidade do método de produzir um conhecimento necessário por si mesmo e aplicável a vastas áreas da experiência humana - um conhecimento tão "necessário" que sua mera descoberta "impõe" a sua aceitação (inclusive sua aceitação "universal", enquanto uma meta-narrativa de explicação sobre o humano).

Em muitas destas crenças, o método deixa de ser apenas uma forma de racionalidade destinada a organizar o pensamento e a ação em determinadas áreas de investigação, como no caso da Psicologia. Rorty (1982) diz que neste sentido estrito, "método" e "racionalidade" são termos aplicados com o intuito de harmonizar o respeito pelas opiniões de nossos colegas e o respeito pelos dados experimentais. Praticar um "método", neste sentido não concebido pela epistemologia tradicional, significa obedecer às convenções normais da disciplina em questão ("normais" no sentido dado por Kuhn, 1962), respeitando aquilo que nela é tido como evidência ou fato, obedecendo sua maneira rotineira de descrever e lidar com a realidade, suas regras e procedimentos, enfim, seguindo certas linhas de investigação consagradas, o que não significa a falta de espaço e abertura para refutação e novas investigações, novos vocabulários descritivos.
Agora, no sentido filosófico pós-cartesiano, diz Rorty, dispor de um método não significa simplesmente poder ordenar nossos pensamentos de acordo com certos critérios ou normas, mas significa que podemos filtrar estes pensamentos com vistas a eliminar elementos tidos como "subjetivos", "não-cognitivos" ou "confusos" (vide item "a", descrito acima), a fim de deixar apenas os pensamentos próprios da Natureza. Na tradição epistemológica, continua Rorty, a distinção entre as partes de nossa mente que correspondem à realidade e as que não o fazem se mescla com a distinção entre formas racionais e não racionais de se fazer ciência. A filosofia (ou Psicologia) centrada na epistemologia precisa de noções de "método" e "racionalidade" para que signifiquem algo mais do que boas maneiras epistêmicas; tais noções devem representar a forma em que a mente está naturalmente capacitada para apreender A Linguagem Própria da Natureza.

Desse modo, e como uma observação geral, poderia dizer que a Psicologia se encontra em dívida com duas demandas concorrentes: de um lado, tem de recorrer ao método para assegurar sua credibilidade científica; de outro, tem de sustentar um discurso, um saber, que prove ser diferente, mais exclusivo ou verdadeiro, do que os outros saberes produzidos pelas outras ciências "concorrentes", ou pela cultura em geral, acerca de algo chamado de "realidade psicológica". Trata-se, portanto, de agarrar-se à epistemologia tradicional e, por conseqüência (na grande maioria das vezes, ingênua e cegamente), à longa tradição filosófica que construiu o discurso moderno ocidental sobre como conhecer as coisas e sobre como chamar as teorias de científicas ou de nãocientíficas (ou de "verdadeira" e "não-verdadeiras"). No fundo, uma tal preocupação com a epistemologia visa a estabelecer níveis de hierarquização no campo socialcientífico, separando e premiando aquelas ciências mais próximas do que Rorty (1982) chama de ideal de autopurificação, vale dizer, mais próximas da verdadeira "objetividade" das coisas, mais próximas do mundo tal como ele é - ou da psique (ou da subjetividade etc.) tal como ela é. A epistemologia, inclusive, pode se revelar como uma causa da competição entre as ciências, competição que culmina em recriminações, disputas e, principalmente, nas estratégias ou logísticas adotadas quando da distribuição de recursos e investimentos etc. É esta dimensão, digamos, político-estratégica que deve ser resgatada, pois a percepção de que a ciência, seja ela qual for, extrai seu poder tão somente de seu respectivo "objeto" de conhecimento é antes uma opção particular do que o cânone da verdadeira essência das coisas, naturais ou não. É, inclusive, um tipo de posição ético-política com sérios e importantes desdobramentos sobre as práticas dos agentes que produzem, divulgam e/ ou aplicam o conhecimento dito psicológico. 
Para concluir com uma retrospectiva, neste texto procurei mostrar como um tipo moderno (no sentido de época moderna, de modernidade) de compreensão do que seja o conhecimento implica na busca por fundamentos, na busca por um estado em que seja possível apreender a real essência das coisas, um ponto para além da cortina de fumaça das aparências do mundo. A epistemologia é apontada como a pedra de toque do discurso moderno. Ela é a tentativa de garantir uma base neutra e metafísica para a produção do conhecimento. Para tanto, foi também de capital importância a invenção, igualmente moderna, da "mente" - para onde converge toda a responsabilidade pela determinação da verdade dos enunciados que representam, acurada e adequadamente, a realidade. A "mente", neste projeto filosófico-epistemológico, pressupõe a figura do sujeito filosófico: palco onde o conhecimento é encenado, produzido, avaliado e enganchado ao mundo. É o sujeito pós-cartesiano, metafísico.

Também procurei mostrar, neste artigo, que a chamada "metafísica da subjetividade", elo que funde as noções de sujeito epistemológico e de "mente" como espelho da realidade, pode estar determinando uma confusão entre as noções filosófica de sujeito e sociológico-psicológica de indivíduo. Tal confusão preserva a longa tradição de dicotomias, iniciada desde Platão, que separam o "conhecimento das coisas" e as "próprias coisas", "subjetivo" e "objetivo", "necessário" e "contingente", "fato" e "valor" etc. Procurei demonstrar que a manutenção da "metafísica da subjetividade" na Psicologia é, em parte, motivada por crenças que perduram, explícita ou implicitamente, em maior ou menor grau, sobre o método, e que tentam garantir um conhecimento puro, universal e que alcance as coisas tal como elas são em sua suposta natureza a priori.

Creio ser fundamental uma revisão séria e aprofundada deste estado de coisas, pois sua manutenção no campo de produção dos saberes psi pode gerar grandes conseqüências éticas que se refletem na arquitetura geral do empreendimento da Psicologia neste século XXI.
Desdobramentos importantíssimos podem daí surgir, como, por exemplo, a compreensão de como tem sido a demanda pela Psicologia nestes tempos, quão útil tem sido o conhecimento psicológico e qual tem sido o teor e o conteúdo das respostas, dadas por esta ciência, às necessidades que emergem do cruzamento das forças que configuram o que hoje entendemos e vivemos como subjetividade, "realidade psicológica", sentimentos, conflitos etc. É o vocabulário da Psicologia que deve ser, em última instância, colocado em questão.

\section{Referências}

Bezerra Jr., B. (1994). Descentramento e sujeito: Versões da revolução coperniciana de Freud. Em J. F. Costa (Org.), Redescrições da psicanálise (pp. 119-167). Rio de Janeiro: Relume Dumará.

Elias, N. (1993). O processo civilizador (R. Jungmann, Trad.). Rio de Janeiro: Zahar. (Original publicado em 1982)

Ghiraldelli Jr., P. (1999). Richard Rorty: A filosofia do novo mundo em busca de mundos novos. Petrópolis: Vozes.

Ghiraldelli Jr., P. (2000). O que é filosofia da educação? Uma discussão metafilosófica. Em P. Ghiraldelli Jr. (Org.), O que é filosofia da educação? (pp. 7-87). Rio de Janeiro: DP\&A.

Ibáñez, T. (1993). Construccionismo y psicología. Revista Interamericana de Psicologia, 28(1), 105-123.

Kuhn, T. (1962). The structure of scientific revolutions. Chicago: University of Chicago Press.

Rorty, R. (1979). Philosophy and the mirror of nature. Princeton: Princeton University Press.

Rorty, R. (1982). Consequences of pragmatism. Minneapolis: University of Minnesota.

Rorty, R. (1985). Habermas and Lyotard on postmodernity. Em R. J. Bernstein (Org.), Habermas and modernity (pp. 161-175). Cambridge/ Massachusetts: MIT Press.

Rorty, R. (1989). Contingency, irony, and solidarity. Cambridge: Cambridge University Press.

Rorty, R. (1991a). Objectivity, relativism, and truth. Cambridge: Cambridge University Press.

Rorty, R. (1991b). Essays on Heidegger and others. Cambridge: Cambridge University Press.

Rorty, R. (1995). Is Truth a goal of inquiry? Davidson versus Wright. The Philosophical Quarterly, 45(180), 282-300.

Rorty, R. (1999). Philosophy and social hope. New York: Penguin.

Recebido: 06/04/2001

Revisado: 27/11/2001

Aceito: $27 / 11 / 2001$

Sobre o autor

Pedro Fernando Bendassolli é Psicólogo formado pela UNESP e Mestrando IP-USP. Membro do Grupo de Estudos e Pesquisas em Pragmatismo e Filosofia Americana (GEP-PFA), no CNPq. Editor executivo do Portal Brasileiro da Filosofia (www.filosofia.pro.br) e Editor do site Psicologia \& Pragmatismo (www.psicologiapedro.hpg.com.br). Manager Editor da revista Pragmatism and American Philosophy, do Pragmatism Archive (USA). 